\section{Assessment of bacterial load in broiler chicken meat from the retail meat shops in Chitwan, Nepal}

\author{
Bhandari N,1* Nepali DB, ${ }^{2}$ Paudyal S1
}

\footnotetext{
${ }^{1}$ Institute of Agriculture and Animal Science, 2Rampur Chitwan Nepal, Department of Livestock Production and Management, Institute of Agriculture and Animal Science
}

*Correspondence to: Mr. Nirajan Bhandari, Institute of Agriculture and Animal Science, Rampur Chitwan, Nepal, email: vetnirajan4nepal@gmail.com, Tel No.: (+977)-9849071674

\begin{abstract}
INTRODUCTION: Keeping quality of meat and meat related food hazard relates to microbes present in the meat during processing or storage. The poultry slaughtered and dressed under Chitwan conditions carrying high initial contamination would be present in meat as inherent contamination in the finished products.
\end{abstract}

MATERIALS AND METHODS: This cross-sectional study included 26 fresh broiler meat samples from registered retail shops. The samples were subjected to bacteriological analysis such as total viable count (TVC), total enterobacteriaceae count (TEC), total coliform count (TCC) and total staphylococcal count (TSC). Also, the samples were analyzed for the detection of Salmonella spp. and identified by different biochemical tests.

RESULTS: The mean counts in $\log _{10} \pm$ SE colony forming units per gram (cfu/g) for Bharatpur, Ratnanagar and Institute of Agriculture and Animal Science (IAAS) vicinity were obtained as $11.1 \pm 0.3,11.5 \pm 0.3$ and $12.2 \pm 0.5$ TVC; $8.5 \pm 0.2$, $9.2 \pm 0.3$ and $10.2 \pm 0.4$ TEC; $6.5 \pm 0.3,7.6 \pm 0.3$ and $8.4 \pm 0.5$ TCC; $6.5 \pm 0.2,6.8 \pm 0.3$ and $7.7 \pm 0.4$ TSC respectively. No samples were found to be within the permissible limits given by different agencies. Prevalence of Salmonella spp. in retail broiler meat in Chitwan was found $46.2 \%$.

CONCLUSION: The retail broiler meat samples from the locations contain high count of bacteria suggesting deplorable state of hygienic and sanitary practices. The presence of Salmonella and Staphyloccus aureus organisms over the permissible limits are of special concern because these account for potential food borne intoxication. So, the need for microbial assessment of fresh meats can be emphasized.

KEY WORDS: Bacterial load, Broiler meat, Chitwan, Salmonella spp., Staphyloccus aureus, Permissible limits

Article submitted 10 July. Reviewed 25 July. Author correction 28 July. Final version accepted 18 August 2013. 


\section{INTRODUCTION}

Meat, a good source of animal protein along with sensory attributes, appeals to the consumers very easily. Meat is the most perishable of all important foods since it contains sufficient nutrient needed to support the growth of microorganisms ${ }^{1}$.Annual production of chicken meat in Nepal is 16662 metric ton and annual production of chicken meat in Chitwan district is 1422 metric ton. So, Chitwan has 8.5 percent share of chicken meat production annually in $\mathrm{Nepal}^{2}$. Chicken meat can be contaminated at several points throughout the processing operations. Moreover, retail cuts could result in greater microbial load owing to large amount of exposed surface area, more readily available water, nutrient and greater oxygen penetration which leads to spoilage of meat ${ }^{3}$.Meat borne zoonotic diseases such as Salmonellosis, Campylobacteriosis, E. coli enteritis and food poisoning by Clostridium, Staphylococcus, etc. are the major problems encountered by the consumers eating contaminated meat. Only little is known about microbial aspects, shelf life and food safety of commercial retail chicken meat in Chitwan. The poultry slaughtered and dressed under Chitwan conditions carrying high initial contamination would be exhibited to the point the consumers are offered as retail meat. So, retail meat would harbour all the bacteria that are already present in meat as inherent contamination through infection and that are introduced during handling, improper dressing, cleaning, insanitary condition and retailing. To increase meat quality, assurance in accordance with microbial load assessment is deemed necessary 4 . Hence, this study was conducted to assess the microbiological situation of fresh chicken meat which can be the reflection of hygienic condition of meat consumed and the possible hazards of public health. The study also compares the bacterial load to the acceptance criteria given by different international agencies since no such criteria for raw chicken meat has been set in Nepal.

\section{MATERIALS AND METHODS}

\section{Study Area}

This was a cross sectional study carried out in 6 months period from July to December 2011. The research was focused on retail broiler meat shops of Ratnanagar Municipality, Bharatpur Municipality and Institute of Agriculture and Animal Science, IAAS vicinity (Mangalpur, Sharadanagar, Gitanagar and Parbatipur VDCs) of Chitwan, Nepal.
Experiments were carried out at Veterinary Microbiology Laboratory of IAAS, Rampur. A total of 26 samples including 13 samples out of 17 registered retail meat shops in Bharatpur Municipality, 9 samples out of 13 registered retail meat shops of Ratnanagar Municipality, and 4 samples out of 4 registered retail meat shops of VDCs around IAAS vicinity (1 from Mangalpur VDC, 1 from Sharadanagar VDC, 1 from Gitanagar VDC and 1 from Parbatipur VDC) were collected by simple random sampling method.

\section{Collection of Samples}

Pooled sampling was done by taking samples from neck, thigh, and breast region by excision weighing a total of $25 \mathrm{~g}$. The samples were stored in sterile sealed polythene bag on crushed ice until microbiological analyses. Samples were collected at time between 9 to $10 \mathrm{am}$. The samples were transported within few hours and analyzed immediately at the Veterinary Microbiology Laboratory of IAAS, Rampur.

\section{Microbiological Analysis of samples}

Two main assessments were performed for bacteriological analysis after collection of samples. Firstly to evaluate sanitary quality of meat, $225 \mathrm{ml}$ of $0.1 \%$ buffered peptone water was transferred into the plastic bag containing $25 \mathrm{~g}$ of meat sample and a homogenized suspension was made. Thus 1:10 dilution of the sample was obtained and later different serial dilutions ranging from $10^{-2}-10^{-13}$ was prepared according to the recommendation of International Organization for Standardization, 19955. All these samples were subjected to bacteriological analysis such as determination of total viable count (TVC), total enterobacteriaceae (TEC), total coliform count (TCC) and total staphylococcal count (TSC). A $100 \mu \mathrm{l}(0.1 \mathrm{ml})$ from serial dilution was used on prepared duplicate plates and spreading was performed for the determination of counts. For this $100 \mu \mathrm{l}$ of each tenfold dilution $\left(10^{-2}-10^{-13}\right)$ was transferred on duplicate agar plates using separate sterilized micro- pipette for each dilution. So, duplicate agar plates prepared using the Nutrient agar (NA), Violet red bile glucose agar(VRBG), MacConkey agar with crystal violet and Baird-Parker agar(BPA) as supplied by HIMEDIA ${ }^{\circledR}$ Pvt Ltd., India were used for determination of TVC,TEC,TCC and TSC respectively. The diluted samples were spread as quickly as possible on the surface of the plate with sterile glass spreader. One sterile spreader was used for each plate. The plates were incubated at $37^{\circ} \mathrm{C}$ for 48 
hours before counting. The plates were interpreted as $<30$ too few to count, $30-300$ counted and $>300$ too many to count. The average number of colonies in particular dilution in particular agar plate was multiplied by the dilution to obtain the total count. The results of the total bacterial count were expressed as the number of colony forming units cfu/per g of meat samples. Bacterial counts were then transformed and represented as $\log 10 \mathrm{cfu} / \mathrm{g}$ of the sample.

Secondly, $25 \mathrm{~g}$ samples were analyzed for the presence or absence of Salmonella spp. For selective isolation of Salmonella, enriched (in buffered peptone water) sample was streaked into Brilliant Green Agar (BGA), MacConkey agar and Xylose Lysine Tergitol 4 (XLT4) agar plates. The inoculated plates were incubated for $48 \mathrm{hrs}$ at $37^{\circ} \mathrm{C}$. The bacterial isolates obtained from the samples were purified by re-streaking them on the same selective media (BGA, MacConkey, XLT4) used for their isolation and were characterized by different biochemical tests as described by Chakraborty ${ }^{6}$ and Quinn et al.7 The biochemical tests such as Triple Sugar Iron (TSI), Oxidase, Catalase, Methyl Red (MR), Voges Proskauer (VP), Urease, Motility, Ornithine decarboxylase, Indole etc. were used for identification of Salmonella spp.

\section{Ethical Approval}

This study was carried out as a part of partial fulfillment of degree of Bachelor of Veterinary Science and Animal Husbandry (B. V. Sc \& A.H) and approved by Institute of agriculture and animal science (IAAS) internship committee. Consents of the shopkeepers were taken before moving to the collection of the samples.

\section{Statistical Analysis}

The recorded data were tabulated using Microsoft Excel 2007. Significant differences were analyzed by ....

Table 1. Mean total counts of retail broiler meat in $\log _{10}$ CFU per gram \pm Standard error (SE)

\begin{tabular}{lllll}
\hline Sample $\mathrm{n}=26)$ & Mean TVC & Mean TEC & Mean TCC & Mean TSC \\
\hline Bharatpur Municipality $(\mathrm{n}=13)$ & $11.1 \pm 0.3^{\mathrm{a}}$ & $8.5 \pm 0.2^{\mathrm{b}}$ & $6.5 \pm 0.3^{\mathrm{b}}$ & $6.448 \pm 0.22^{\mathrm{b}}$ \\
Ratnanagar Municipality $(\mathrm{n}=9)$ & $11.5 \pm 0.3^{\mathrm{a}}$ & $9.2 \pm 0.3^{\mathrm{b}}$ & $7.6 \pm 0.3^{\mathrm{a}}$ & $6.8 \pm 0.3^{\mathrm{b}}$ \\
VDCs around IAAS $(\mathrm{n}=4)$ & $12.2 \pm 0.5^{\mathrm{a}}$ & $10.2 \pm 0.4^{\mathrm{a}}$ & $8.4^{\mathrm{a}} 0.5^{\mathrm{a}}$ & $7.7^{\mathrm{a}} \pm 0.4^{\mathrm{a}}$ \\
F-value & $1.800^{\mathrm{ns}}$ & $5.769^{* *}$ & $8.545^{* *}$ & $3.673^{*}$ \\
\hline
\end{tabular}

ns= non significant

Single asterisk $(*)=$ statistically significant at $\mathrm{P}<0.05$

Double asterisk $\left(^{* *}\right)=$ statistically significant at $\mathrm{P}<0.01$

Means in the column with different superscript letters ( $\mathrm{a}$ and b) are significantly different $(P<0.05)$. one-way ANOVA using MSAT-C version 1.3(1994). For mean comparison, LSD at $\mathrm{P}<0.05$ was performed. Correlation analysis was done for between the agars. Descriptive statistics was used to describe the result of prevalence analysis. Prevalence was estimated as the number of samples detected positive to Salmonella spp. isolation from the total sample analyzed.

\section{RESULTS}

\section{Total viable count (TVC)}

The result presented in Table 1 reveals that the mean value of the TVC of broiler meat of Bharatpur Municipality, Ratnanagar Municipality and that of VDCs around IAAS Rampur Campus did not differ significantly with mean counts of $\log _{10} \mathrm{cgu} /$ gram being $11.1 \pm 0.3,11.5 \pm 0.3$ and $12.2 \pm 0.5$ respectively.

\section{Total Enterobactereaceae count (TEC)}

The analysis of variance revealed a highly significant difference $(p=0.0093)$ for TEC. The TEC for Bharatpur Municipality was found to be $8.5 \pm 0.2$ and that of Ratnanagar Municipality and VDCs around IAAS as $9.2 \pm 0.3$ and $10.2 \pm 0.4$ respectively. However, mean counts for both the municipalities didn't exhibit significant differences as shown by LSD.

\section{Total Coliform Count (TCC)}

Highly significant difference $(\mathrm{p}=0.0017)$ was also noted for the TCC. Significant difference in TCC was found in the municipalities with mean counts being $6.5 \pm 0.3$ and $7.6 \pm 0.3$. The highest coliform load was found in the VDCs around IAAS vicinity having mean count of $8.4 \pm 0.5$.

\section{Total Staphylococcal count (TSC)}

Significant difference at $(\mathrm{p}=0.043)$ was found in case of TSC of the retail broiler meat shops. The 
Table 2. Summarized results of bacteriological examination of samples in comparison with the standards

\begin{tabular}{|c|c|c|c|}
\hline $\begin{array}{r}\text { Samples } \\
\text { Type of analysis }\end{array}$ & $\begin{array}{c}\text { Bharatpur } \\
\text { Municipality }(n=13)\end{array}$ & $\begin{array}{c}\text { Ratnanagar } \\
\text { Municipality }(n=9)\end{array}$ & VDCs around IAAS $(n=4)$ \\
\hline TVC permissible limit by ICMSF,1986 & $\begin{array}{l}\log _{10} 7 \text { (for raw chicken, } \\
\text { fresh or frozen) }\end{array}$ & $\log _{10} 7$ & $\log _{10} 7$ \\
\hline No. of samples within the limit & 0 & 0 & 0 \\
\hline No. of samples exceeding the limit & 13 & 9 & 4 \\
\hline $\begin{array}{l}\text { TCC permissible limit by Directive } \\
88 / 657 / \text { EEC,BIS } 1969\end{array}$ & $\log _{10} 2$ & $\log _{10} 2$ & $\log _{10} 2$ \\
\hline No. of samples within the limit & 0 & 0 & 0 \\
\hline No. of samples exceeding the limit & 13 & 9 & 4 \\
\hline $\begin{array}{l}\text { TSC permissible limit by Directive } \\
88 / 657 / \text { EEC }\end{array}$ & $\log _{10} 2$ & $\log _{10} 2$ & $\log _{10} 2$ \\
\hline No. of samples within the limit & 0 & 0 & 0 \\
\hline No. of samples exceeding the limit & 13 & 9 & 4 \\
\hline $\begin{array}{l}\text { Salmonella permissible limit by Directive } \\
88 / 657 / \text { EEC,BIS } 1969 \\
\text { No. of samples within the limit(absent) }\end{array}$ & Absent in 25 grams & Absent in 25 grams & Absent in 25 grams \\
\hline $\begin{array}{l}\text { No. of samples exceeding the limit } \\
\text { (present) }\end{array}$ & $\begin{array}{l}8 \\
5\end{array}$ & $\begin{array}{l}6 \\
3\end{array}$ & $\begin{array}{l}0 \\
4\end{array}$ \\
\hline
\end{tabular}

Since, no such standards have been recommended for the permissible limit of raw poultry meat in Nepal, the European Economic Committee (EEC) provision for raw meat ${ }^{8}$, Bureau of Indian Standards (BIS) ${ }^{9}$ and International Commission on Microbiological Specifications for Foods(ICMSF) ${ }^{10}$ has been used for comparison.

Table 3. Prevalence of Salmonella spp. in Chitwan

\begin{tabular}{llccc}
\hline Sn & Sites & Total samples & $\begin{array}{c}\text { Positive for } \\
\text { Salmonella }\end{array}$ & $\begin{array}{c}\text { Prevalence of } \\
\text { Salmonella (\%) }\end{array}$ \\
\hline 1 & Bharatpur Municipality & 13 & 5 & 38.5 \\
2 & Ratnanagar Municipality & 9 & 3 & 33.3 \\
3 & VDCs Around IAAS & 4 & 4 & 100 \\
Total & & 26 & 12 & 46.2 \\
\hline
\end{tabular}

LSD analysis found no significant differences in count between the two municipalities having mean count of $6.5 \pm 0.2$ and $6.8 \pm 0.3$. But the count of both municipalities differed significantly to that of VDCs around IAAS which had highest mean count of $7.7 \pm 0.4$.

\section{Prevalence of Salmonella spp.}

A total of 26 retail broiler meat samples of Chitwan district (2 Municipalities and 4 VDCs around IAAS) were processed for isolation of Salmonella. Out of the total samples tested, Salmonella was detected from 12 samples ( 5 from Bharatpur Municipality, 3 from Ratnanagar Municipality and 4 from VDCs around IAAS). Thus prevalence of Salmonella in Chitwan was found to be $46.2 \%$ which is shown in table 3.

\section{DISCUSSION}

The results were higher than those obtained for fresh poultry meat samples in Slaughter Slabs of Kathmandu valley, Nepal. ${ }^{11}$ Also very high count were found than those obtained in local chicken market with non-sophisticated outlets of Bangalore, India. ${ }^{12}$ Similarly, the TVC was also greater than that found in chicken meat samples collected from retailers in Tabriz, Iran which was $5.1 \pm 0.1$ in terms of $\log _{10} \mathrm{cfu} /$ gram \pm SE. ${ }^{13}$ The high TVC in the examined samples reported here indicate that the contamination of the product could be attributed to unsatisfactory sanitation during handling and processing.

For raw chicken meat, the TEC values are very high 
and indicate high contamination of both coliform and non-coliforms which form the majority of Gram negative pathogens. ${ }^{14}$ The coliform contamination was found highest in the VDCs which may be due to non sophisticated slabs and poor hygiene of the retail shops. The results are very high than those obtained for fresh poultry meat samples in Slaughter Slabs of Kathmandu valley, Nepal (2 $\left.\log _{10} \mathrm{cfu} / \mathrm{g}\right) .{ }^{11}$ Also the results are higher than those from Iran which was found to be $4.0 \pm 0.1 .^{13}$

The presented data revealed that, the Staphylococcus aureus counts were found at highest number in case of VDCs at an average of $7.7 \pm 0.4$ $\log _{10} \mathrm{cfu} / \mathrm{g}$ where as similar counts were found for both Bharatpur and Ratnanagar municipalities at averages of $6.5 \pm 0.2$ and $6.8 \pm 0.3$ respectively. These results are higher than those obtained in local chicken market with non-sophisticated outlets of Bangalore, India which were at an average of $4.2 \pm 0.1 \log _{10} \mathrm{cfu} / \mathrm{g} .12$ The use of hand evisceration technique along with infrequent hand washing could be the cause of such a high occurance of this bacteria.

Results presented in table 2 declared that, all of the examined samples of raw chicken meat had TVC $>\log _{10} 7 \mathrm{cfu} / \mathrm{g}$ which exceeded the permissible limit recommended by the ICMSF, 1986. Similarly, none of the samples were in agreement with TCC permissible limit by Directive 88/657/EEC, BIS 1969 and TSC permissible limit by Directive 88/657/EEC. For Salmonella spp,8 samples out of 13 in Bharatpur Municipality and 6 samples out of 9 in Ratnanagar Municipality were in agreement with the standard given by Directive 88/657/EEC and BIS 1969. However,none were in agreement with the standard in case of 4 samples of VDCs around IAAS Rampur Campus.

According to this study prevalence of Salmonella in retail broiler meat in Chitwan was found to be 46.2 $\%$ which is higher than that obtained by Dhakal and Manandhar(12\%) ${ }^{15}$; and by Acharya $(26.1 \%)^{16}$ for Chitwan Valley. However, this prevalence rate is lower than that of Tiwari who isolated $47.8 \%$ Salmonella in poultry meat in Chitwan ${ }^{17}$. This difference can be related to difference in time and season of research from those researches.

\section{CONLUSIONS}

The marked growth of bacteria concludes that retail broiler meat is not suitable for consumption. The high total viable counts recorded in this study showed the microbial diversity (differences in form or species) in these places, condition of the market and the hygienic practice employed by meat sellers and butchers. The presence of Salmonella and Staphyloccus aureus organisms demonstrates a potential health risk since the organisms are pathogenic and gives warning signal for the possible occurrence of food borne intoxication The need for microbial assessment of fresh meats and other meat products processed and packaged for human consumption is therefore emphasized and recommended to reduce possible hazard.

\section{CONFLICT OF INTEREST: None to declare}

FINANCIAL INTEREST: None to declare. This research was carried out from the financial assistance provided by IAAS, office of Dean for the internship period of six months.

\section{REFERENCES}

1. Magnus P. Meat Composition. Food Science and Technology, 4th edition. Gohumunary Pub London 1981:108-215.

2. MOAC. 2009, 2010. Statistical Information on Nepalese Agriculture. HMG, Agri- Business Promotion and Statistics Division. Ministry of Agriculture and Coperatives, Singha Durbar, Kathmandu, Nepal.

3. Ayres, C.P. 1995. Microbiology of Spoilt Food and Food Stuffs. Food Microbiol J 16:266-280

4. Yousuf AHM, Ahmed MK, Yeasmin S, et al. Prevalence of Microbial load in Shrimp, Penaeus monodon and Prawn, Macrobrachium rosenbergii from Bangladesh. World J Agric Sc 2008: 4:852-855.

5. ISO. Recommendation of the meeting of subcommittee, International Organization for Standardization on meat and meat products.ISO/TC36/Sc-6. The Netherlands 1995:10-18.

6. Chakraborty, P. A text book of microbiology, 2nd edition, New Central Book Agency, Calcutta, India. 2003.

7. Quinn PJ, Carter ME,Markey B and Carter GR. Clinical Veterinary Microbiology. Mosby International, London. 1998.

8. Gracey JF,Collins DS and Huey RI.Meat Hygiene.10 ${ }^{\text {th }}$ edition,W.B Saunders Company Ltd.10th edition.1999:359

9. BIS. Recommended Microbiological Standards for Meat and Meat Products.Bureau of Indian Standards.1969. 10. ICMSF. Microorganism in foods; samples for Microbiological Analysis: Principles and Specific applications. Recommendation of the International Commission on Microbiological Specification for Foods. Association of Microbiological Societies. Toronto, University of Toronto Press.1986

11. Maharajan R. Study on Microbial Load in Poultry Meat from Different Slaughter Slabs of Kathmandu Valley. A B.V.Sc \& A.H. Internship thesis submitted to Purbanchal University, 2009.

12. Ruban SW, Fairoze N. Effect of Processing Conditions on Microbiological quality of market Poultry meats in Bangalore, India. J Anim Vet Adv 2011:10:188-191. 
13. Javadi A, Safarmashaei S. Microbial profile of marketed broiler meat. Middle-East J Sci Res 2011;9:652-656

14. Chordash, R.A. and N.F. Insalate.1978.Incidence and Pathological Significance of Escherichia coli and other Sanitary Indicator Organisms in Food and Water. J Food Technol 10:54-63

15. Dhakal IP, Manandhar P. Isolation of Salmonella in the Pooled Samples of Litter, Food and Water in Chitwan Poultries. In: Proceedings on National Poultry Expo-2005, Chitwan, December 15-19,2005;43-46.

16. Acharya B, Isolation of Salmonella in Poultry meat in Kathmandu, Lalitpur, Bhaktapur, Chitwan district. A B.V.Sc. \& A.H. Internship thesis submitted to Tribhuvan University, 2007.

17. Tiwari R. Isolation and Identification of Salmonella from Broiler in Chitwan district. Internship thesis submitted to Tribhuvan University, 2002.

\section{Citing this article}

Bhandari N, Nepali DB, Paudyal S. Assessment of bacterial load in broiler chicken meat from the retail meat shops in Chitwan, Nepal. Int J Infect Microbiol 2013;2(3):99-104. 